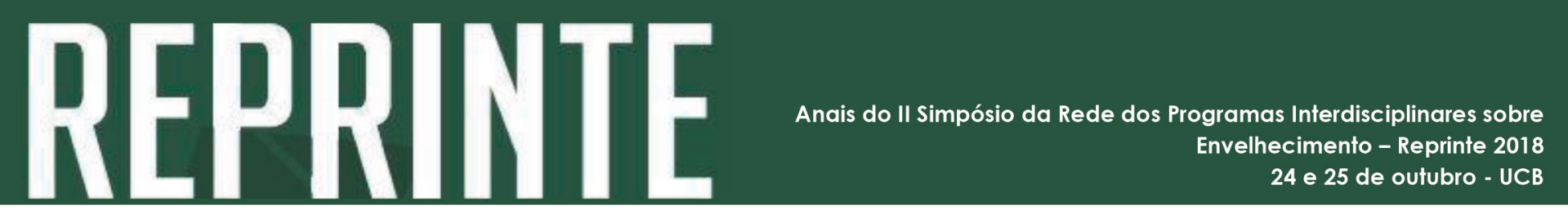

http://dx.doi.org/10.5335/rbceh.v16i1.10469

\title{
26) NUTRINFORM: Desenvolvimento de aplicativo para auxílio do manejo de sintomas gastrintestinais em idosos
}

Joyce de Sousa Diniz ${ }^{1}$

\section{Resumo}

Palavras-chave: Envelhecimento; Sinais e sintomas digestórios; Tecnologia.

\section{Introdução}

A gerontologia considera o envelhecimento como um fenômeno biológico. Sendo assim, faz-se necessário definir quais são consideradas as alterações digestivas prováveis que podem ocorrer ao longo do avanço da idade, visto que essas são partes fisiológicas do envelhecimento (GRASSI et al, 2011; HELBOSTAD et al, 2017). Nota-se que a cada dia a tecnologia torna-se melhor e mais acessível nos quesitos financeiros e de acessibilidade (MALWADE et al, 2018). A gerontecnologia caracteriza-se por sua interdisciplinaridade, associando gerontologia e tecnologia (CREBER et al, 2016).

\section{Objetivos}

Desenvolver um aplicativo para dispositivos móveis para auxílio do manejo de sintomas gastrintestinais em idosos por meio de orientações nutricionais.

\section{Métodos}

Trata-se de um estudo prospectivo de caráter experimental. Será desenvolvido um aplicativo, com o auxílio de profissional especializado, seguindo as etapas de desenvolvimento, as quais englobam o levantamento dos requisitos solicitados pelo pesquisador, elaboração do projeto, implementação, teste e por fim, implantação do aplicativo. A aplicação realizar-se-á

Mestranda no Programa de Pós-Graduação em Gerontologia da Universidade Católica de Brasília. Endereço para correspondência: QS 07 Lote 01 - EPCT - 71966-700 - Águas Claras - Taguatinga - DF. Email: joysdiniz@gmail.com 
em idosos ( $\geq 60$ anos), independentes, sem histórico de diagnóstico de demência e que façam uso frequente de dispositivos móveis.

\section{Resultados esperados}

A associação entre tecnologia e conhecimentos de saúde pode ser a peça chave no que diz respeito à busca da qualidade de vida justa para os idosos. Almeja-se com esta pesquisa que a adesão à utilização do aplicativo desenvolvido, favoreça o manejo correto dos sintomas gastrintestinais, por meio de orientações nutricionais específicas, apresentando-se simples e acessível, tanto ao idoso, quanto a seus familiares e cuidadores, favorecendo o acesso imediato a informações essenciais. Partindo desse pressuposto, a assistência nutricional tende a mostrar-se mais eficaz, visto que, a melhora dos sintomas gastrintestinais influencia de maneira direta na manutenção do estado nutricional, englobando as variáveis de aceitação dietética, padrão alimentar e perda ponderal. Além disso, o acompanhamento nutricional será capaz de abranger informações mais completas e fidedignas, resultando em melhorias significativas no tratamento dos idosos.

\section{Referências}

CREBER, R.M.M.; HICKEY, K.T.; MAURER, M.S. Gerontechnologies for Older Patients with Heart Failure: What is the Role of Smartphones, Tablets, and Remote Monitoring Devices in Improving Symptom Monitoring and SelfCare Management? Curr Cardiovasc Risk Rep. 2016:10(10):30.

GRASSI, M. et al. Changes, functional disorders, and diseases in the gastrointestinal

HELBOSTAD, JL. et al. Mobile Health Applications to Promote Active and Healthy Ageing. Sensors. 2017:17(3):622.

MALWADE, S. et al. Mobile and Wearable Technologies in Healthcare for the Ageing Population. Computer Methods and Programs in Biomedicine. 2018: 161:233-237. tract of elderly. Nutr Hosp. 2011;26(4):659-668. 